\title{
Observation on the Host Parasitoid Interaction between Periplaneta americana, the American Cockroach and Tetrastichus hagenowii, an Oothecal Parasitoid
}

\author{
R Srinivasan, KN Panicker
}

\author{
Vector Control Research Centre (ICMR), Indira Nagar, Pondicherry, 605 006, India
}

\begin{abstract}
Investigations were carried out on the host parasitoid interaction between Periplaneta americana, the American cockroach and Tetrastichus hagenowii, an oothecal parasitoid. This gregarious female parasitoid infected and or oviposited in only one host and caused $100 \%$ mortality of the infected host. However, increase in parasitoid density decreased the progeny production and influenced the sex ratio. The progenies produced were male biased. When host preference was tested by offering oothecae of different species of cockroaches, $\mathrm{T}$. hagenowii showed a predilection towards the oothecae of P. americana, suggesting its host specificity.
\end{abstract}

Key words: cockroach - parasitoid - host parasitoid interaction-biological control potential

Tetrastichus hagenowii (RATZEBURG) (Hymenpotera: Eupelmidae), a gregarious parasitoid has been reported to attack the othecae of Periplaneta americana LINNAEUS (Dictyoptera: Blattellidae) in nature (Uma \& Sankaran 1979). T. hagenowii known to have a wide distribution and has been reported from India, Australia, Saudi Arabia, Taiwan, Trinidad and the USA (Vargas \& Fallas 1974, Fleet \& Frankie 1975, Kanayama et al. 1976). It has an obligatory association with the oothecae of $P$. americana, for its survival and propagation (Uma 1984) and has been shown to control the pest effectively (Roth \& Willis 1957). Though extensive investigations have been carried out on the life cycle of this parasitoid (Usman 1949, Roth \& Willis 1954, Cameron 1955, Edmund 1955), information on its host parasitoid interaction is still scanty. The present study was undertaken to fill this gap.

\section{MATERIALS AND METHODS}

Tetrastichus hagenowii obtained from Institute of Health Research, Bangkok, Thailand was propagated in the laboratory on five to ten days old oothecae of $P$. americana. The infected oothecae were kept in $250 \mathrm{ml}$ plastic containers for possible emergence of either parasitoids or cockroach nymphs.

Studies were carried out on the oviposition pattem by exposing five to ten days old oothecae of $P$. americana to mated, gravid female parasitoids. Fresh oothecae were provided daily until the death of the last parasitoid. The developmental duration of different stages of the parasitoid was also investigated. For this purpose, infected oothecae of $P$. americana were dissected in $0.9 \%$ normal saline and examined for the presence of eggs, larvae and pupae of $T$. hagenowii. Eggs were mounted in glycerine, while larvae and pupae were cleared in Sinton's fluid (chloral hydrate, phenol and lactic acid in the ratio of $2 / 1 / 1$ ) and mounted in glycerine for observation under microscope. Duration of all immature stages was calculated based on the stages of development. Fecundity and longevity of the parasitoids were also calculated.

Investigations on the effect of host density on parasitism was carried out by exposing gravid female parasitoids and hóst in the ratio $1 / 1,1 / 2$, $1 / 3,1 / 4,1 / 5$ and $1 / 10$. Similarly influence of parasitoid density on parasitism was also studied subjecting parasitoids and hosts in different ratios, 1/1, 2/1,3/1, 4/1,5/1 and 10/1. Each set was replicated five times. To test whether superparasitism influences the deposition of eggs, ovary of the females in each replicate was dissected and examined for egg retention soon after oviposition.

To find out the host preference, the gravid female parasitoids were exposed to the oothecae of $P$. americana, $P$. australasiae, $P$. brunnea, Neostylopyga rhombifolia and Supella longipalpa collected from field. The oothecae were held separately in containers for the emergence of parasitoids or nymphs. The entire study was carried out under controlled temperature $\left(28 \pm 2{ }^{\circ} \mathrm{C}\right)$ and relative humidity $60-70 \%$.

\section{RESULTS AND DISCUSSION}

Freshly emerged males and females of $T$. hagenowii measured $1.0-1.5 \mathrm{~mm}$ (mean $=1.2 \pm$ 0.2 ) and $1.7-2.2 \mathrm{~mm}$ (mean $=1.9 \pm 0.1$ ) respectively and they were sexually mature at the time of emergence. Male to female ratio was 1/8.08. The adults emerged inside the othecae and es- 
caped through a hole, which they made by chewing the oothecal wall. The mode of locomotion is mainly by walking or hopping, rarely flying. Mating was completed within 8 to $10 \mathrm{sec}$ (mean $=8.8 \pm 0.8)$. When a healthy ootheca was exposed to the gravid female parasitoid on the day of emergence, it readily accepted and started ovipositing. Prior to deposition of eggs, it examined the ootheca with antennae and tapped the surface with ovipositor for $2.5 \mathrm{~min}$ (mean $=3.4$ \pm 1.2 ). After exploring a suitable site, it drilled a hole by slowly inserting the stylet. The eggs were deposited by inserting the ovipositor through this hole. The entire process lasted from $75-90 \mathrm{~min}$ (mean $=83.4 \pm 5.0$ ). The number of eggs laid by a female in an ootheca ranged from 43-104 eggs (mean $=71.4 \pm 22.4$ ). The fecundity of $T$. hagenowii observed in the present investigation is higher than that of earlier report (Cameron 1955). However, each female oviposited in only a single ootheca in its entire life causing $100 \%$ mortality of the infected host.

The incubation period of eggs ranged from 25 days (mean $=4.0 \pm 1.27$ ) while larval and pupal duration varied from 18-29 days (mean $=23.6 \pm$ 4.0 ) and $10-15$ days (mean $=11.8 \pm 1.8$ ) respectively. The entire duration of immature development ranged from $30-49$ days (mean= $38.3 \pm 6.8$ ). The starved males and females were found to live for $1-2$ days $($ mean $=1.2 \pm 0.45$ ) and $1-4$ days (mean $=2.7 \pm 1.03$ ) respectively, whereas honey fed males and females lived 2-4 days (mean $=2.8$ \pm 0.8 ) days and $4-9$ days (mean $=6.7 \pm 2.1$ ) respectively.

When the effect of host density on parasitism was studied, the fermales infected/oviposited in only one host; from the remaining host oothecae, nymphs of $P$. americana emerged.

When the effect of parasitoid density on parasitism was studied, the mean number of eggs laid by a female did not differ significantly
$(\mathrm{R}=0.7683 ; \mathrm{T}=2.0517 ; \mathrm{p}=0.0001)$ from each other, but the production of the progeny was found to be reduced significantly $(R=0.8638$; $\mathrm{T}=3.4289 ; \mathrm{p}=0.02656$ ), which indicates that superparasitism eliminated the supernumeries. Besides, with increase in the number of developing larvae in the superparasitised oothecae the duration of immatures decreased significantly $(\mathrm{R}=0.8771 ; \mathrm{T}=3.6522 ; \mathrm{p}=0.02172)$ and the sex ratio changed in favour of males (Table). In $T$. hagenowii, the males perhaps, because of their rapid development and lower nutritional requirements, fared relatively better as survival decreased. The dry weight of both males and females emerged from the superparasited host was also significantly lower $(P=0.015)$ than that of the normal brood host, witnessing the influence of dietary stress on developing progenies. This finding confirms with that of Ikawa and Susuki (1982), Suzuki et al. (1984) and Uma (1984).

Luck et al. (1982) reported that in gregarious parasitoids, the survival of offsprings in superparasitised host is always high as the larvae do not fight and physiological suppression usually does not occur. Furthermore, gregarious females have an advantage to superparasitism in order to adjust their brood size. This adjustment has an evolutionary significance, where the female becomes resistant for inbreeding, which result in the allocation of female biased sex ratio and ultimately the population perpetuates (Waage \& Greahead 1986).

When the parasitoid was offered the oothecae of $P$. americana, B. germanica, $P$. australasiae, $P$. brunnea, $N$. rhombifolia and $S$. longipalpa, it oviposited only in the ootheca of $P$. americana. Though, Cameron (1955) reported that this species has been identified from the oothecae of $B$. orientalis, $B$. germanica, $P$. americana and $P$. australasiae, in the present investigation the

TABLE

The density effect of the parasitoid Tetrastichus hagenowil, on the progeny production, developmental duration and sex ratio from the ootheca of Periplaneta americana

\begin{tabular}{|c|c|c|c|c|c|}
\hline \multirow{2}{*}{$\begin{array}{c}\text { Ratio of } \\
\text { parasitoids } \\
\text { to host }\end{array}$} & \multicolumn{2}{|c|}{ Progeny survival } & \multicolumn{2}{|c|}{$\begin{array}{l}\text { Developmental } \\
\text { period (days) }\end{array}$} & \multirow{2}{*}{$\frac{\text { Sex }}{\text { Male: Female }}$} \\
\hline & Range & Mean & Range & Mean & \\
\hline $1: 1$ & $43.0-104.0$ & $71.4 \pm 22.4$ & $30-49$ & $38.3 \pm 6.8$ & $1: 8.08$ \\
\hline $2: 1$ & $49.0-96.5$ & $73.7 \pm 20.1$ & $25-41$ & $35.2 \pm 6.2$ & $1: 8.25$ \\
\hline $3: 1$ & $32.7-70.3$ & $47.6 \pm 14.9$ & $27-45$ & $34.5 \pm 6.7$ & $1: 5.53$ \\
\hline $4: 1$ & $24.5-74.5$ & $45.5 \pm 18.1$ & $29-34$ & $31.7 \pm 6.9$ & $1: 2.41$ \\
\hline $5: 1$ & $7.0-23.4$ & $16.8 \pm 6.4$ & $28-38$ & $32.2 \pm 6.6$ & $1: 2.38$ \\
\hline 10:1 & $5.9-24.3$ & $14.2 \pm 7.4$ & $27 \cdot 33$ & $30.0 \pm 6.5$ & $1: 0.91$ \\
\hline
\end{tabular}


parasitoid preferred the oothecae of $P$. americana, even though all the host oothecae were of same age. This suggests its circumscribed host specificity. However, this finding conflicts with the observations of Fleet and Frankie (1975) and Roth and Willis (1954) and agrees with the finding of Harlan and Kramer (1981).

The results of this finding proves that $T$. hagenowii has an obligatory association with its host, $P$. americana for survival, propagation and existence. Besides, the parasitoid has been reported to posses a wide array of searching strategy to locate their host in nature using chemical cues (Lewis \& Tumlison 1988). Considering these facts the parasitoid, $T$. hagenowii can be advocated as an effective bio-control agent against the cockroach, $P$. americana.

\section{ACKNOWLEDGEMENTS}

To Dr Vijai Dhanda, Director, Vector Control Research Centre, Pondicherry for his critical review of the manuscript and to Sri $P$ Kumaran and Sri $R$ Vasudevan for technical assistance.

\section{REFERENCES}

Cameron E 1955. On the parasites and predators of the cockroach, Tetrastichus hagenowii (Ratz.). Bull Entomol Res 46: 137-147.

Edmund LR 1955. Biological notes on Tetrastichus hagenowii (Ratzeburg), a chalcidoid parasite of cockroach eggs (Hymenoptera: Eulophidae: Orthoptera: Blattidae). Ann Entomol Soc Am 48: 210213.

Fleet RR, Frankie GW 1975. Behavioural and ecological characteristics of an eulophid egg parasite of two species of domiciliary cockroaches. Environ Entomol 4: 282-284.

Harlan NJ, Kramer RD 1981. Limited host specificity in Tetrastichus hagenowii (Ratzeburg). J Ga Ent 16: 67-70.

Ikawa T, Susuki Y 1982. Ovipositional experience of the gregarious parasitoids Apanteles glomeratus
(Hymenoptera: Braconidae). Appl Ent Zool 17: 119-126.

Kanayana A, Yoshida E, Houma $T$ 1976. The parasitism by Tetrastichus hagenowii, on oothecae of smoky brown cockroach, Periplaneta fulginosa, collected in Shizuka city. Jap J Sani Zool 27: 157. 162.

Lewis WJ, Tumlison JH 1988. Host detection by chemically mediated associative leaming in a parasitic wasp. Nature 331: 257-259.

Luck RF, Podoler H, Kfir R 1982. Host selection and egg allocation behaviour by Aphyris melinus and $A$. lingnanensis: Comparision of two facultatively gregarious parasitoids. Ecol Ent 7: 397-408.

Roth LM, Willis ER 1954. The biology of the cockroach egg parasite Tetrastichus hagenowii (Hymenoptera: Eulophidae). Trans Am Entomol Soc 80: 53-72.

Roth LM, Willis ER 1957. The medical and veterinary importance of cockroaches. Sinithsonian Misc Coll 34: $1-147$.

Susuki Y, Tsuji, Sasakawa M 1984. Sex allocation and the effects of superparasitism on secondary sex ratios in the gregarious parasitoids, Trichogramma chilonis (Hymenoptera: Trichogrammatidae). Ani Beh 33: 1223-1227.

Uma NA 1984. Comparative studies of Tetrastichus hagenowii (Ratzeberg) and $T$. asthenogmus (Waterson), two primary parasites of cockroach oothecae and on their hyper-parasite Tetrastichus sp. ( $T$. miser (Nes) group) (Hymenoptera : Eulophidae). Bull Ent Res 74: 175-189.

Uma NA, Sankaran T 1979. Domiciliary cockroaches and their oothecal parasitoids in India. Entomophaga 24: 276-279.

Usmans S 1949. Some observations on the biology of Tetrastichus hagenowii (Ratz.). An egg parasite of the house-cockroach (Periplaneta americana L.). Ain Sci 11: 407-408.

Vargas MV, Fallas FB 1974. Notes on the biology of Tetrastichus hagenowii (Hymenoptera:Eulophidae) a parasite of cockroach oothecae. Entomol News 85: 23-26.

Waage F, Greathead 1986. Insect parasitoid. Acadernic Press Inc. (London) Lid, London, xvii p. 389 pp. 